\section{OPHTHALMOLOGICAL TRAINING OF MEDICAL STUDENTS.}

THE Council of British Ophthalmologists has issued a report dealing with the teaching and examination of medical students in ophthalmology. The first part of the report reviews briefly the efforts made up to the present by the General Medical Council to ensure better training of the medical student in this important subject. These, unfortunately, have not succeeded in their object, and it is still the case that "the general body of the medical profession does not possess a competent knowledge of diseases of the eye."

The second part of the report deals in detail with the requirements of all the examining bodies in Great Britain and Ireland and, for comparative purposes, with a large number of Colonial, American, and foreign universities. The analysis of these requirements shows that Great Britain stands almost alone in granting diplomas to practise medicine without evidence of an adequate knowledge of diseases of the eye. In Ireland and in the great majority of foreign and Colonial universities ophthalmology is one of the subjects of the qualifying examination, and the examinations in it are conducted by ophthalmic surgeons.

The council has therefore recommended (I) that no student shall be admitted to the final examination, qualifying to practise medicine, unless he has attended an ophthalmic clinic for not less than six hours a week during a period of three months, and has attended a course of svstematic instruction in ophthalmology; and (2) that no student shall be considered to have passed the qualifying examination unless he has shown a sound knowledge of practical ophthalmology in an examination conducted by ophthalmic surgeons.

\section{CLOCK ESCAPEMENTS. ${ }^{1}$}

$T$ HE most ancient instruments for measuring time were probably some kind of sundial. Something of the kind is, no doubt, referred to in 2 Kings $x x$. and Isaiah xxxviii., where it is stated that the shadow moved back ten steps on the steps of Ahaz (for that is the literal translation). Herodotus ("Euterpe," cix.) tells us that the Babylonians introduced to the Greeks the $\pi$ ó $\boldsymbol{x}_{o s}$ and the $\gamma \nu \dot{\omega} \mu o \nu$, no doubt some forms of sun-instruments. Frequent allusions are found in the classics to the clepsydra, which was made in various forms, always depending, however, upon the approximately uniform flow of water through a small hole.

But clocks, properly so called, cannot be traced with certainty earlier than the fourteenth century. In $\mathrm{I} 348$ a curious iron clock was sent over from Switzerland, and was until recently kept in Dover Castle. It is now in the Science Museum at South Kensington. It is interesting as having no pendulum or balance-spring (both much later inventions), but, instead, a vertical spindle carrying a horizontal traverse loaded at the ends with weights. This vertical spindle has two pallets projecting from its sides, approximately at right angles to each other, which engage alternately the uppermost and lowermost tooth of a contrate wheel the axis of which is horizontal and in the same plane with the vertical axis first referred to. This is the "verge". escapement, which was for long afterwards used in both clocks and watches. No good timekeeping was possible with such an arrangement. Gravity did not come

1 From a discurse delivered at the Royal Institution on February $2 x$ by A. T. Hare.

NO. 2582 , VOL. IO3] into the problem, and the speed of the movement was only restrained by its energy having alternately to create and destroy angular momentum in the swinging arms. The force of the train, however variable, was paramount.

The next step in horology, and undoubtedly the most important which has ever been made, was the application of the pendulum to clocks by the Dutch physicist and astronomer, Christian Huygens, in 1657. Galileo had discovered, about sixty years earlier, the isochronism (since found to be only approximate) of a swinging body, but, in spite of efforts made after his death to claim priority for him in the invention of the pendulum clock, the evidence has not convinced historians of his title to that honour.

Huygens, being aware of the fact that the motion of a particle under gravity was only isochronous, independently of the extent of the arc of swing, when the body describes a cycloid, and knowing the property of that curve to reproduce itself as an involute of an equal cycloid, attempted to secure the desired isochronism by suspending his pendulum from a silk thread which swung between two cheeks of brass cut to the shape of the cycloid, thus obliging the bob to trace an involute. But the silk was so affected by the weather that no good result ensued.

Another objection to the verge escapement was the large arc of swing necessary to permit the escapement to unlock itself. Huygens attempted to overcome this difficulty by making the verge the axis, not of the pendulum-crutch, but of a pinion gearing into a larger wheel to the arbor of which the crutch was attached. This construction permitted the angle of swing to be reduced at pleasure, but more friction was introduced, and little improvement was effected.

The calculation of the time of swing of a free pendulum describing a circular arc can only be made approximately, but the approximation can be carried as far as desired, and as the arc of swing is never large, a few terms suffice. This is the formula :-

$$
\mathrm{T}=\frac{\pi k}{2 \sqrt{g h}}\left(\mathrm{I}+\frac{\mathrm{I}}{4} \sin ^{2} \frac{a}{2}+\frac{9}{64} \sin ^{4} \frac{a}{2}+\ldots\right)
$$

from which, by differentiation,

$$
\frac{d \mathrm{~T}}{d a}=\frac{\pi k \sin a}{\mathrm{I} 6 \sqrt{g h}}\left(\mathrm{I}+\mathrm{I} 8 \sin ^{2}{ }_{2}^{a}+\ldots\right) .
$$

Here $T$ is the time of swing of the pendulum from its highest position to the vertical, and $\alpha$ is the semiangle-that is, the angle turned through from the highest to the lowest position. Now of the factors making up the expressions on the right-hand side of these equations, only $\pi$ and $g$ and the numerical coefficients can really be considered as constant. It has been suggested that even $g$ may one day be shown to be variable. As for $h$ and $k$-that is, the distance from the axis of motion to the centre of gravity and the radius of gyration respectively-these are well known to be dependent on temperature, and an interesting account might be given, if time permitted, of the evolution of the compensated pendulum. The recent discovery of alloys of iron and nickel the coefficient of expansion of which is very low has much facilitated this.

The factor which has most influence on the value of $T$ is $\alpha$, the angle of swing. The formulæ show us two things: first, that the wider the arc of swing the more a clock will lose, and, secondly, that a given small variation of arc is less harmful when the whole arc is small than when it is great. There are practical reasons, however, for not making it too small, which have led to the adoption of arcs of two or three degrees on each side of the vertical as, on the whole, the best. 